\section{UJMM

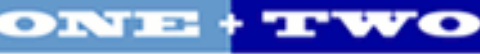

Volume 6 | 2016 Spring 2016

\section{Undergraduate Journal of Mathematical}

Modeling: One + Two

Article 4

2016

\title{
Analysis of Adiabatic Batch Reactor
}

Erald Gjonaj

University of South Florida

Advisors:

Arcadii Grinshpan, Mathematics and Statistics

Scott Campbell, Chemical and Biomedical Engineering

Laura Anderson, Chemistry

Problem Suggested By: Scott Campbell

Follow this and additional works at: https://digitalcommons.usf.edu/ujmm

Part of the Mathematics Commons

UJMM is an open access journal, free to authors and readers, and relies on your support:

Donate Now

\section{Recommended Citation}

Gjonaj, Erald (2016) "Analysis of Adiabatic Batch Reactor," Undergraduate Journal of Mathematical Modeling: One + Two: Vol. 6: Iss. 2, Article 4.

Available at: https://digitalcommons.usf.edu/ujmm/vol6/iss2/4 


\title{
Analysis of Adiabatic Batch Reactor
}

\begin{abstract}
A mixture of acetic anhydride is reacted with excess water in an adiabatic batch reactor to form an exothermic reaction. The concentration of acetic anhydride and the temperature inside the adiabatic batch reactor are calculated with an initial temperature of $20^{\circ} \mathrm{C}$, an initial temperature of $30^{\circ} \mathrm{C}$, and with a cooling jacket maintaining the temperature at a constant of $20^{\circ} \mathrm{C}$. The graphs of the three different scenarios show that the highest temperatures will cause the reaction to occur faster.
\end{abstract}

\section{Keywords}

reactor, adiabatic batch, acetic anhydride

\section{Creative Commons License}

(c) (i) ()

This work is licensed under a Creative Commons Attribution-Noncommercial-Share Alike 4.0 License. 


\section{PROBLEM STATEMENT}

Hydrolysis of acetic anhydride occurs in the following manner:

$$
\left(\mathrm{CH}_{3} \mathrm{CO}\right)_{2} \mathrm{O}+\mathrm{H}_{2} \mathrm{O} \rightarrow 2 \mathrm{CH}_{3} \mathrm{COOH}
$$

The goal of this project is to determine the reaction time needed for the hydrolysis of acetic anhydrate in an adiabatic batch reactor. A batch reactor is one in which the reactants are inserted into the reactor and the reactants are left uninterrupted until the process has ended. An adiabatic batch reactor is insulated in order to prevent any heat exchange with its surroundings. The reaction is a second order chemical reaction, but due to the fact that it will be run with large amounts of $\mathrm{H}_{2} \mathrm{O}$ it gains the ability to act as a pseudo-first order reaction.

The adiabatic batch reactor model for the disappearance of acetic anhydride (A):

$$
\frac{d C_{A}}{d t}=-k C_{A}
$$

In this equation $C_{A}$ is the variable for the acetic anhydrate in $\mathrm{kmol} / \mathrm{m}^{3}, t$ is the time in minutes, and $k$ is the reaction rate constant. The reaction rate constant will be:

$$
k=k_{0} e^{-a / T}
$$

where $T$ is the temperature in Kelvin, $k_{0}=24.15 \times 10^{6} / \mathrm{min}$ and $a=5,627 \mathrm{~K}$.

The equation for the energy balance:

$$
\frac{d T}{d t}=-\frac{k C_{A} \Delta H}{\rho C_{p}}
$$

where $\Delta H=-209,000 \mathrm{~kJ} / \mathrm{kmol}$ is the heat released by the reaction, $p=1050 \mathrm{~kg} / \mathrm{m}^{3}$ and $C_{p}=3.8 \mathrm{~kJ} / \mathrm{kgK}$ are the density and heat capacity of the reaction mixture, respectively. The initial concentration of acetic anhydride in the reactor is $C_{A}^{0}=0.5 \mathrm{kmol} / \mathrm{m}^{3}$. Assume an initial temperature of $20^{\circ} \mathrm{C}$. 
We determine the time required to reach $95 \%$ conversion of acetic anhydride for an initial temperature of $20^{\circ} \mathrm{C}$. How would this change if the starting temperature was $30^{\circ} \mathrm{C}$ ? How long would it take to reach $95 \%$ conversion if a cooling jacket was used to maintain the temperature at $20^{\circ} \mathrm{C}$ during the reaction? Conversion $x$ is defined as:

$$
x=\frac{C_{A}^{0}-C_{p}}{C_{A}^{0}} .
$$

\section{MOTIVATION}

Accurately identifying the temperature reached and concentration of reactants left in an adiabatic batch reactor is relevant to fields pertaining to the prediction of temperatures in chemical reactions, such as chemical engineering and process engineering. Batch reactors are also used in small scale laboratory applications, for instance, the production and inducting of fermentation of beverage products. Batch reactors are greatly used in the field of waste water treatment because of their effectiveness in reducing the biological oxygen demand of waste water.

The goal of this project is to find the temperature and concentration of acetic anhydride in the adiabatic batch reactor, where the initial concentration is $0.5 \mathrm{kmol} / \mathrm{m}^{3}$. The model will be run at an initial temperature of $20^{\circ} \mathrm{C}, 30^{\circ} \mathrm{C}$ and $20^{\circ} \mathrm{C}$ with a cooling jacket for the batch reactor to maintain a constant temperature.

\section{MATHEMATICAL DESCRIPTION AND SOLUTION APPROACH}

What makes this project non-trivial is the need to solve both equation (2) and (4) simultaneously. Since the reaction is exothermic, heat will be released and the temperature inside the adiabatic reactor will increase (Fritzler, Dharmavaram and Hartrim). Equation (2) has two variables; $C_{A}$, which is dependent directly to time, and $k$, which is directly dependent on temperature, which 
in turn is directly dependent on time because of the equation (4). Thus the reaction constant, $k$, is indirectly dependent on time, hence the following would be a better representation of the equation:

$$
\frac{d C_{A}}{d t}=-k[T(t)] C_{A}(t)
$$

Equation (6) cannot be solved by integration because it has two variables that are either implicitly or explicitly dependent on time. The same reason applies to the second equation, in which $k$ is implicitly dependent on time, and $C_{A}$ directly dependent on time. Furthermore, equation (6) cannot be solved by simple integration. A better representation of equation (6) is:

$$
\frac{d T}{d t}=-k[T(t)] C_{A}(t) \frac{\Delta H}{p C_{p}} .
$$

Before solving equation (6) and (7) there is a need to find the initial reaction rate. This can be found by using equation (3), thus we have:

$$
k=k_{0} e^{-a / T}=(24,150,000) e^{-(5,267) /(293.15)}=0.111341 / \min
$$

Equation (8) gives the rate of the initial reaction, which allows us to start solving equation (6) and (7) by using Euler's method (James).

$$
y^{\prime}(t)=f(t, y), \quad y\left(t_{0}\right)=y_{0}, \quad y_{n+1}=y_{n}+\Delta t f\left(t_{n}, y_{n}\right)
$$

The $\Delta t$ denotes the change in time, $t_{n}$ denotes the current value time value of the equation, $y_{n}$ denotes the current value of the function at time $n$, and $y_{n+1}$ denotes the value of the function at time $n+1$. The next step in this problem is to solve equation (6) by using Euler's method and substituting the values of $k$. To approximate equation (6), one needs to use Euler's method, the following equation is thus obtained:

$$
C_{A}\left(t_{n+1}\right)=C_{A}\left(t_{n}\right)-k[T(t)] C_{A}\left(t_{n}\right) \Delta t
$$


By using equation (10) the value of the concentration for the first time step can be found. As a reminder, the initial concentration is $C_{A}=0.5 \mathrm{kmol} / \mathrm{m}^{3}$ and the change in time is $\Delta t=0.05$ :

$$
C_{A}\left(t_{n+1}\right)=0.05-(0.111341)(0.5)(0.05)=0.497216 \mathrm{kmol} / \mathrm{m}^{3}
$$

This is the value of the concentration at $t=0.05$. By using this value the approximation for temperature can be found. The first step to finding the temperature is to approximate the value for equation (7) by using Euler's method (9). The formula derived is the following:

$$
T\left(t_{n+1}\right)=T\left(t_{n}\right)-k\left[T\left(t_{n}\right)\right] C_{A}\left(t_{n}\right) \frac{\Delta H}{p C_{p}} \Delta t .
$$

The initial temperature, $T_{0}$, is $293.15 \mathrm{~K}$ and

$$
T_{1}=293.15-(0.111341)(0.497216) \frac{(-209,000)}{(1,050)(3.8)}(0.05) .
$$

This model shows the temperature approximation for time $\Delta t=0.05$ minute. The method of approximation would continue, by finding the new reaction constant, $k$ by using equation (8), which would then be substituted into equation (10) to obtain the concentration, $C_{A}$. Lastly the value for the concentration and reaction constant are substituted into equation (12) to find the temperature. By following this procedure for every value, one is able to approximate the time it will take for $95 \%$ of the reactants to convert. To find the $95 \%$ conversion concentration a rewritten form of equation (5) is used:

$$
x=\frac{C_{A}^{0}-C_{A}}{C_{A}^{0}} \Rightarrow C_{A}=(1-x) C_{A}^{0}=(1-0.95)(0.5)=0.025 \mathrm{kmol} / \mathrm{m}^{3}
$$

The value obtained in equation (14) gives us the end concentration for the model. By following this model the final temperature, time and reaction constant is found. Based on the values found by following Euler's method with an initial temperature of $20^{\circ} \mathrm{C}$, the following graphs were 
found for temperature and concentration with respect to time. The data tables for the following graphs can be found in Appendix 1, Section A.

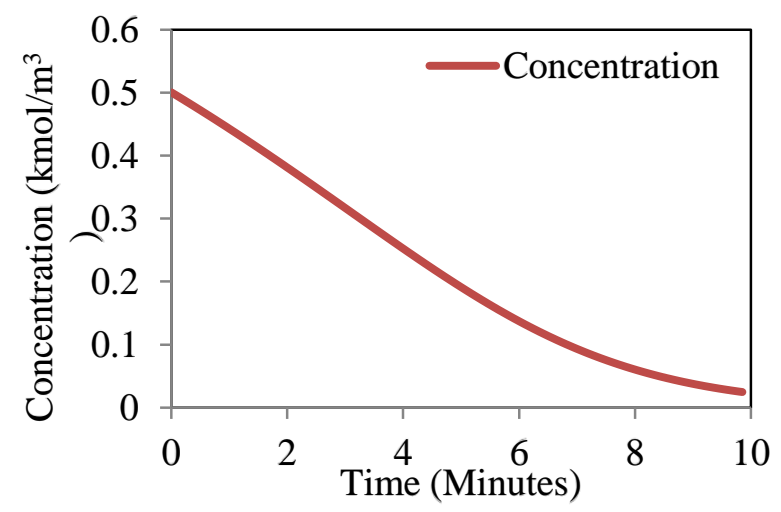

Figure 1: Adiabatic batch reactor reactant concentration with respect to time with an initial temperature of $20^{\circ} \mathrm{C}$.

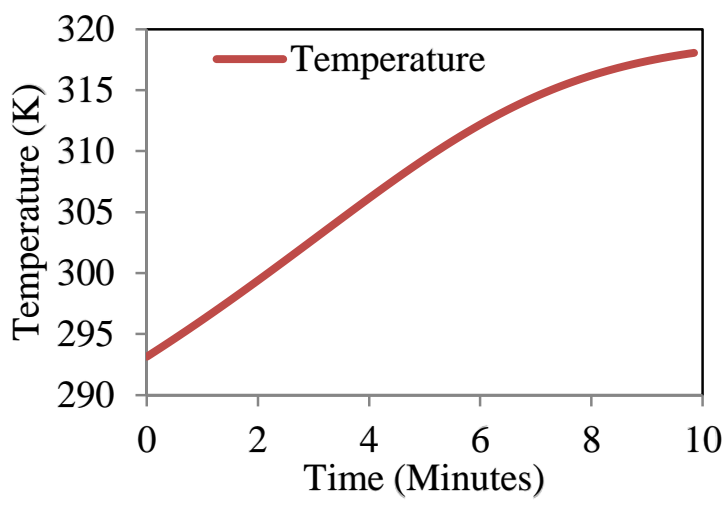

Figure 2: Adiabatic batch reactor temperature reached with respect to time with an initial temperature of $20^{\circ} \mathrm{C}$ approximation by using Euler's method.

The same procedure was used for the reaction to occur at an initial temperature of $30^{\circ} \mathrm{C}$, or $303.15 \mathrm{~K}$. The graphs for concentration and temperature with respect to time are as follows. The table values for the following graphs can be found in Appendix 1, Section B.

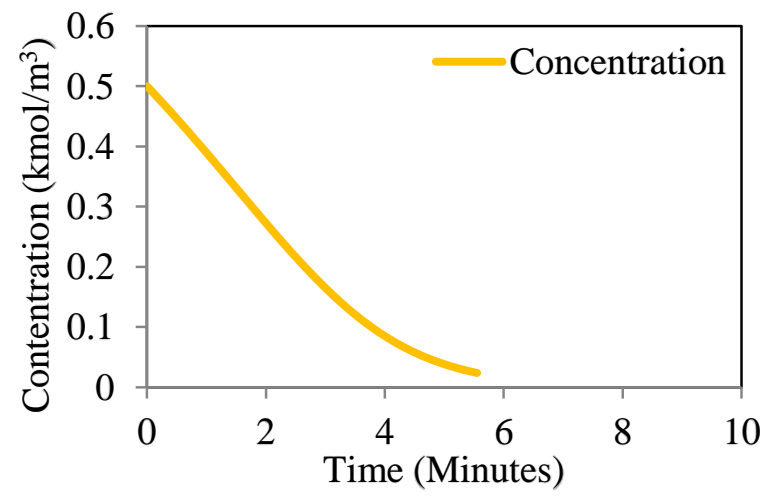

Figure 3: Adiabatic batch reactor reactant concentration with respect to time with an initial temperature of $30^{\circ} \mathrm{C}$.

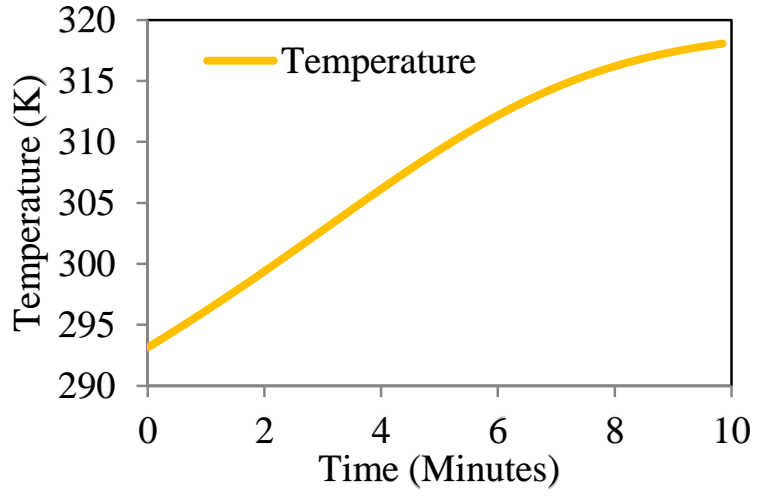

Figure 4: Adiabatic batch reactor temperature reached with respect to time with an initial temperature of $30^{\circ} \mathrm{C}$ approximation by using Euler's method. 


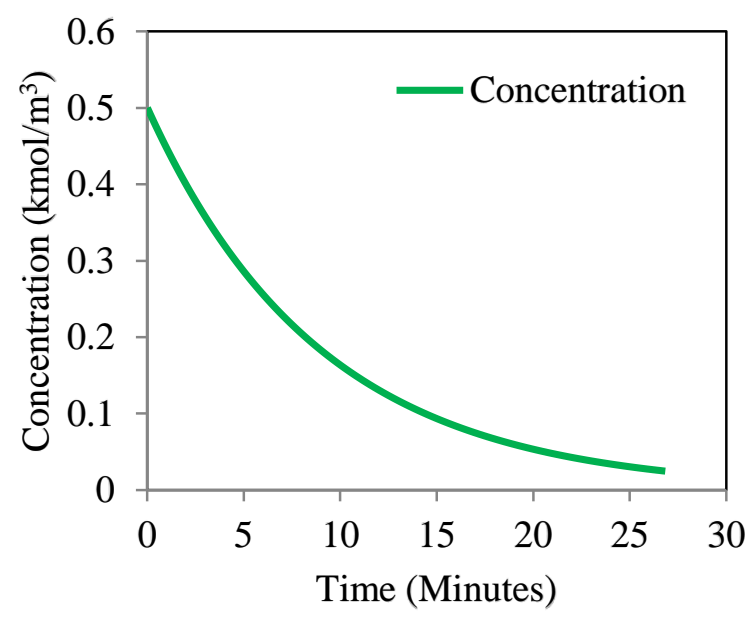

Figure 5: Adiabatic batch reactor with a cooling jacket concentration of reactants at a constant temperature of $20^{\circ} \mathrm{C}$.

The model was also run using an adiabatic batch reactor with a cooling jacket to maintain the temperature at $20^{\circ} \mathrm{C}$. For this model only the graph of the concentration with respect to time will be shown because the temperature was maintained at a constant of $293.15 \mathrm{~K}$ or $20^{\circ} \mathrm{C}$.

Lastly, for ease of comparison, the concentration of all three models and the temperature of the first two models are displayed.

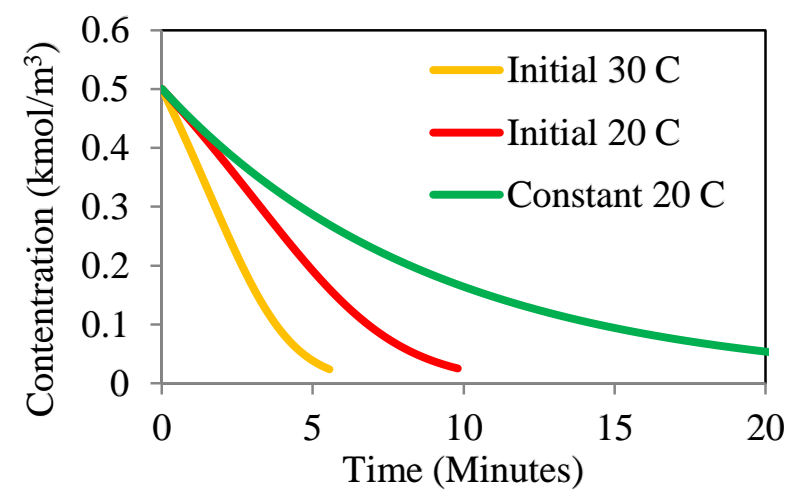

Figure 6: Adiabatic batch reactor concentrations at initial $30^{\circ} \mathrm{C}, 20^{\circ} \mathrm{C}$, and constant $20^{\circ} \mathrm{C}$.

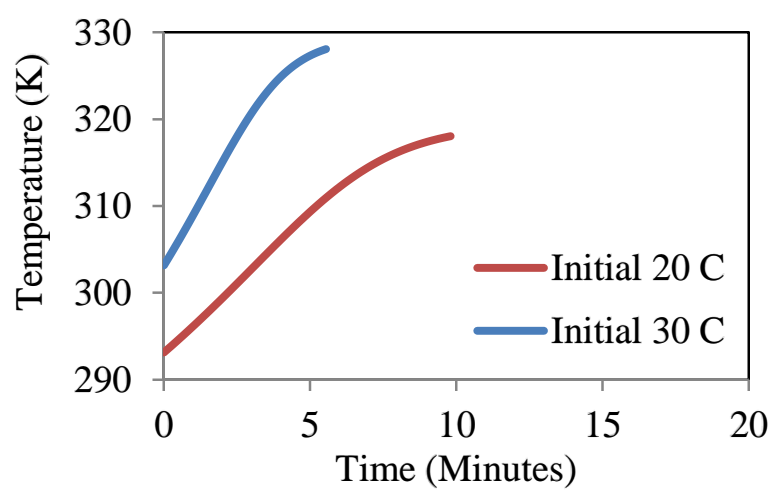

Figure 7: Adiabatic batch reactor temperature elevations with initial temperature $20^{\circ} \mathrm{C}$ and $30^{\circ} \mathrm{C}$.

The table of values for this graph can be found in Appendix A, section C. 


\section{DISCUSSION}

The results obtained from Euler's marching method were unsurprising. The highest initial temperature, $30^{\circ} \mathrm{C}$, had the shortest reaction time and highest reaction rate. This reaction only took 5.55 minutes, compared to the slower $20^{\circ} \mathrm{C}$ initial model which took 9.85 minutes to reach the point of $95 \%$ reacted. The model with a constant temperature of $20^{\circ} \mathrm{C}$ took 26.85 minutes, and was the slowest.

According to the Kinetic Molecular Theory of Matter, the higher kinetic energy possessed by a substance translates to the particles of that substance having a greater probability of colliding with one another. The greater number of collisions increases the probability of the molecules colliding in the ideal manner, thus forming more products at a faster rate than the same reaction at a lower temperature.

The fact that the higher temperature transcribes into faster reaction rates is evident in the time taken in all three models for concentration to reach its minimum. The slowest reaction occurred in a constant $20^{\circ} \mathrm{C}$, or $293.15 \mathrm{~K}$, the lowest temperature, further affirming that the energy of the reaction is the deciding factor in concluding the reaction rate.

Moreover, the release of heat in both models, initial $20^{\circ} \mathrm{C}$ and initial $30^{\circ} \mathrm{C}$, is equal, although the reaction times are different. The final temperature of the model with a temperature initiated at $20^{\circ} \mathrm{C}$, or $293.15^{\circ} \mathrm{K}$, is $311.1249^{\circ} \mathrm{K}$, and for the model with a temperature initiated at $30^{\circ} \mathrm{C}$, or $303.15^{\circ} \mathrm{K}$, the final temperature is $321.5528^{\circ} \mathrm{K}$. The difference between the final temperatures of these two models is equal to the initial temperature difference between them. This is true because the change in temperature in units of Kelvin is equal to the change in temperature in units of Celsius. The equal change in temperature in both models illustrates how the reaction will release the same amount of heat, disregarding the rate of the reaction and the 
temperature it is conducted in. The tables of values for the end temperatures are included in Appendix A, Section A, B, C.

\section{CONCLUSION AND RECOMMENDATIONS}

The fastest reaction occurred when the model of the adiabatic batch reactor was launched at a temperature of $30^{\circ} \mathrm{C}$. This is expected because the higher temperature allows for the rate of the reaction to increase faster than the reaction rate in the other two models. The lowest temperature model, the constant $20^{\circ} \mathrm{C}$, provided the slowest reaction. Additionally, the model that had the second highest temperature reached, initiated at $20^{\circ} \mathrm{C}$, occurred the second fastest.

Furthermore, a fact that requires attention is the change in heat of the reactions. Both reactions released enough heat to increase the temperature of the adiabatic batch reactor by $25 \mathrm{~K}$ (Asiedu and Hildebrandt). This phenomenon shows that the rate of the reaction is irrelevant regarding the total release of heat, and that the heat released will be equal regardless of the temperature the reaction is started in.

Recommendations for future projects would be to resolve the hydrolysis of acetic anhydrate using Heun's method, instead of Euler's. This will provide more accurate results compared to that of Euler's method. Additionally, one could possibly increase the initial concentration of acetic anhydride in the reactor to see if the reaction constant will plateau after a certain amount of time. 


\section{NOMENCLATURE}

\begin{tabular}{|c|c|c|}
\hline Symbol & Description & Value \\
\hline$\overline{C_{A}^{0}}$ & Initial concentration of acetic anhydrate & $\mathrm{kmol} / \mathrm{m}^{3}$ \\
\hline$\Delta t$ & Time step in Euler's method & $\min$ \\
\hline$k$ & Reaction Constant & $\min ^{-1}$ \\
\hline$\Delta H$ & Heat of reaction & $\mathrm{kj} / \mathrm{mol}$ \\
\hline$p$ & Density of the mixture & $\mathrm{kg} / \mathrm{m}^{3}$ \\
\hline$C_{p}$ & Heat capacity of the mixture & $\mathrm{kj} / \mathrm{kgK}$ \\
\hline$C_{A}$ & Concentration of acetic anhydrate at a specific time & $\mathrm{kmol} / \mathrm{m}^{3}$ \\
\hline$T_{0}$ & Initial Temperature & $\mathrm{K}$ or ${ }^{\circ} \mathrm{C}$ \\
\hline$T_{1}$ & Next approximated temperature for time 1 & $\mathrm{~K}$ or ${ }^{\circ} \mathrm{C}$ \\
\hline$k_{0}$ & Rate of reaction constant & $\min ^{-1}$ \\
\hline$a$ & Constant in the reaction constant equation & $\mathrm{K}$ \\
\hline$y^{\prime}(t)$ & Derivative of the function with respect to $t$ & \\
\hline$y_{n}$ & Value of the function at $t=n$ & \\
\hline$y_{n+1}$ & Value of the function at $t=(n+1)$ & \\
\hline$C_{A}\left(t_{n+1}\right)$ & The value of the concentration in the next time step & \\
\hline$T\left(t_{n+1}\right)$ & The value of the temperature in the next time step & \\
\hline$C_{A}\left(t_{n}\right)$ & Concentration at time $\mathrm{n}$ & \\
\hline$k[T(t)]$ & Concentration at a certain temperature at a certain time & \\
\hline
\end{tabular}




\section{REFERENCES}

Anderson, Laura. Interview. Erald Gjonaj. 2014.

Asiedu, N and D Hildebrandt. "Kinetic Modeling of the Hydrolysis of Acetic Anhydride at Higher Temperatures using Adiabatic Batch Reactor (Thermos-Flask)." Journal of Chemical Engineering \& Process Technology 4.9 (2013): 2-5.

Campbell, Scott. Interview. Erald Gjonaj. 2014.

Fritzler, B.C., et al. "Acetic Anhydride Hydrolysis at High Acetic Anhydride to Water Ratios." International Journal of Chemical Kinetics 46.3 (2014): 151-160.

Grinshpan, Arcadii. Interview. Erald Gjonaj. 2014.

James, Glyn. Advanced Modern Engineering Mathematics. Prentice Hall, 2011.

McGraw-Hill. McGraw-Hill Concise Encyclopedia of Physics. McGraw-Hill, 2004.

Qin, L., Y. Liu and J.H. Tay. "Effect of Settling Time on Aerobic Granulation in Sequence Batch Reactor." Biochemical Engineering Journal 21.1 (2004): 47-52. 